\title{
Influence of dopant metal ions on the formation of cordierite using Combined SAXS/WAXS and EXAFS/WAXS Techniques
}

\author{
Gopinathan Sankar ${ }^{1}$, Andy Dent ${ }^{2}$, Barry Dobson ${ }^{3}$, and Wim Bras ${ }^{4}$ \\ ${ }^{1}$ Department of Chemistry, University College London, 20 Gordon Street, London WC1H 0AJ, \\ United Kingdom \\ ${ }^{2}$ Diamond Light Source, Harwell Campus, Didcot OX11 0DE, United Kingdom \\ ${ }^{3}$ Sagentia Ltd, Harston Mill, Harston, Cambridge CB22 7GG, United Kingdom \\ ${ }^{4}$ Netherlands Organisation for Scientific Research (NWO), DUBBLE@ESRF, CS40220, \\ 38043 Grenoble Cedex 9, France
}

\begin{abstract}
Time-resolved combined scattering and spectroscopic techniques were used to understand in detail the formation of cordierite ceramic from two sources, (a) zeolite B and (b) cordierite glass systems. Time-resolved in situ combined EXAFS/XRD (at the Zn K-edge) investigation of the zinc oxide mixed zeolite B reveal that a series of transformations occur before the formation of cordierite ceramic. In particular the study revealed that addition of small amounts of zinc oxide promote the transformation of cordierite, through the formation of $\mathrm{ZnAl}_{2} \mathrm{O}_{4}$, at lower temperatures compared to the system without zinc oxide. Using in situ time-resolved SAXS/WAXS technique chromium doped in the cordierite glass system was investigated which revealed that, in addition to the formation of phase pure cordierite phase some amount of $\mathrm{MgCr}_{2} \mathrm{O}_{4}$ spinel phase are also produced.
\end{abstract}




\section{Introduction}

Lolite is the legendary gemstone which helped the Vikings navigate the Atlantic Ocean by helping them to find the sun's position even on overcast days by using thin pieces of this gem as polarizing filters [1]. Nowadays one can safely say that the role in navigation has been taken over by more modern methods and that the high quality specimens of this mineral are mainly used in jewelry. A more common form of this mineral generally goes by the name Cordierite, after the $18^{\text {th }}$ century French mineralogist Pierre Louis Antoine Cordier, and is a relatively rare magnesium iron aluminium cyclosilicate mineral. The basic composition of the pure mineral is $\mathrm{Mg}_{2} \mathrm{Al}_{4} \mathrm{Si}_{5} \mathrm{O}_{18}$ but in nature obviously many variations on this can be found and a more general composition is given by $(\mathrm{Mg}, \mathrm{Fe})_{2} \mathrm{Al}_{3}\left(\mathrm{AlSi}_{5} \mathrm{O}_{18}\right)$.

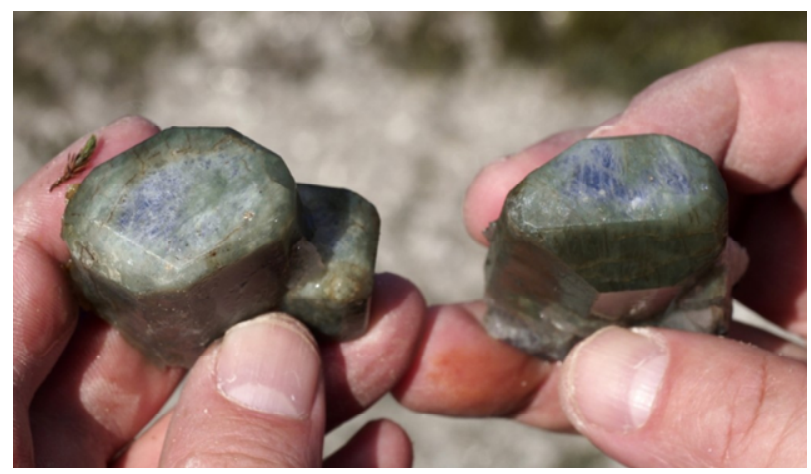

Figure 1. Naturally occurring cordierite specimens found in the Norwegian coastal area. The specimens have the characteristic blue colour. Thin platelets of specimens like this of high optical quality could have been used by Vikings as polarization filters to determine the sun position during overcast days[2]. Photograph @Jan Kihle

Although the industrial use of natural cordierite is rather limited there is an extensive production of synthetic cordierite and of glass ceramics with the base cordierite composition. Surprisingly the applications cover a very wide range from simple household goods like pizza baking plates to more complex and low volume, but high added value, applications like the packaging material of high performance electronic chips. In the automotive industry the usage of cordierite ceramics in catalytic converters and diesel soot filters started in the middle of the seventies and is now widespread and can be considered to be a very mature technology with a high sales volumes. Especially the glass ceramics, with an elemental composition similar to the naturally occurring cordierite mineral, are popular materials. This can be ascribed to several material properties that make this material suitable for applications where a combination of 
resistance to thermal degradation, low thermal expansion coefficient, high thermal conductivity and good mechanical shock resistance are required.

The manufacture of cordierite based materials can be done in several ways; subjecting a bulk glass with the cordierite composition to a thermal treatment or sol-gel technology or partial melting in a mixture of powdered components ('talc path') or thermally collapsing a magnesium exchanged zeolite $\mathrm{B}$ structure (ideal composition of zeolite $\mathrm{B}$ is $\mathrm{Na}_{4} \mathrm{Al}_{4} \mathrm{Si}_{5} \mathrm{O}_{18}$ ) [3], to name a few. Whilst these processes employ temperatures in excess of $1000{ }^{\circ} \mathrm{C}$, there is always a drive to find means of reducing the manufacturing temperature. Therefore, addition of small amounts of cations have been investigated, in particular $\mathrm{Zn}^{2+}$ and $\mathrm{Cr}^{3+}$ as both have spinel forming capabilities. In order to gain a more complete understanding of the fundamentals of the chemical process, in particular, restructuring and crystallization it is necessary to use time-resolved tools which can render structural information over several length scales and also allow for the elucidation of the changes in the chemical state of some of the elements that play a key role in these transforming processes.

The realization that a simultaneous/combination of Synchrotron based X-ray techniques and the development of sample environments which, not only could create the conditions with respect to temperature, pressure and chemical environment but also allow access for the experimental probes required for time-resolved in situ studies. In the area of synchrotron based $\mathrm{X}$-ray probes available in various beamlines, allowed the development of combination of techniques with the appropriate time-resolution to be applied. These combinations could be those of X-rays with non X-ray based probes like Differential Scanning Calorimetry (DSC), Raman spectroscopy etc. [4], or combinations of two X-ray based techniques like X-Ray Diffraction (XRD) and Quick EXAFS (QUEXAFS) [5], or XRD with Small Angle X-ray Scattering (SAXS) [6]. Obviously the study of cordierite ceramic formation was not the single problem for which such combinations were required, but many other areas, in particular heterogeneous catalysis, solid-state reactions and many others [7-13].

The reason why there are still so many unanswered questions about the occurrence and manufacture of cordierite by using thermal methods can be understood when one inspects a high temperature phase diagram [14]. Figure 2 shows an isothermal section $\left(1460{ }^{\circ} \mathrm{C}\right)$ of the phase diagram. It shows a binary range of cordierite solid solutions which is surrounded by multiphase regions also containing liquid fractions. In such a complicated system it should not 
come as a surprise that slight local compositional deviations can lead to different structures. In this case the crystallization enhancers in the form of metallic additions can play a crucial role and it is important that this role is understood [15-20]. The same is true for temperature differences and gradients and probably even pressure [21].

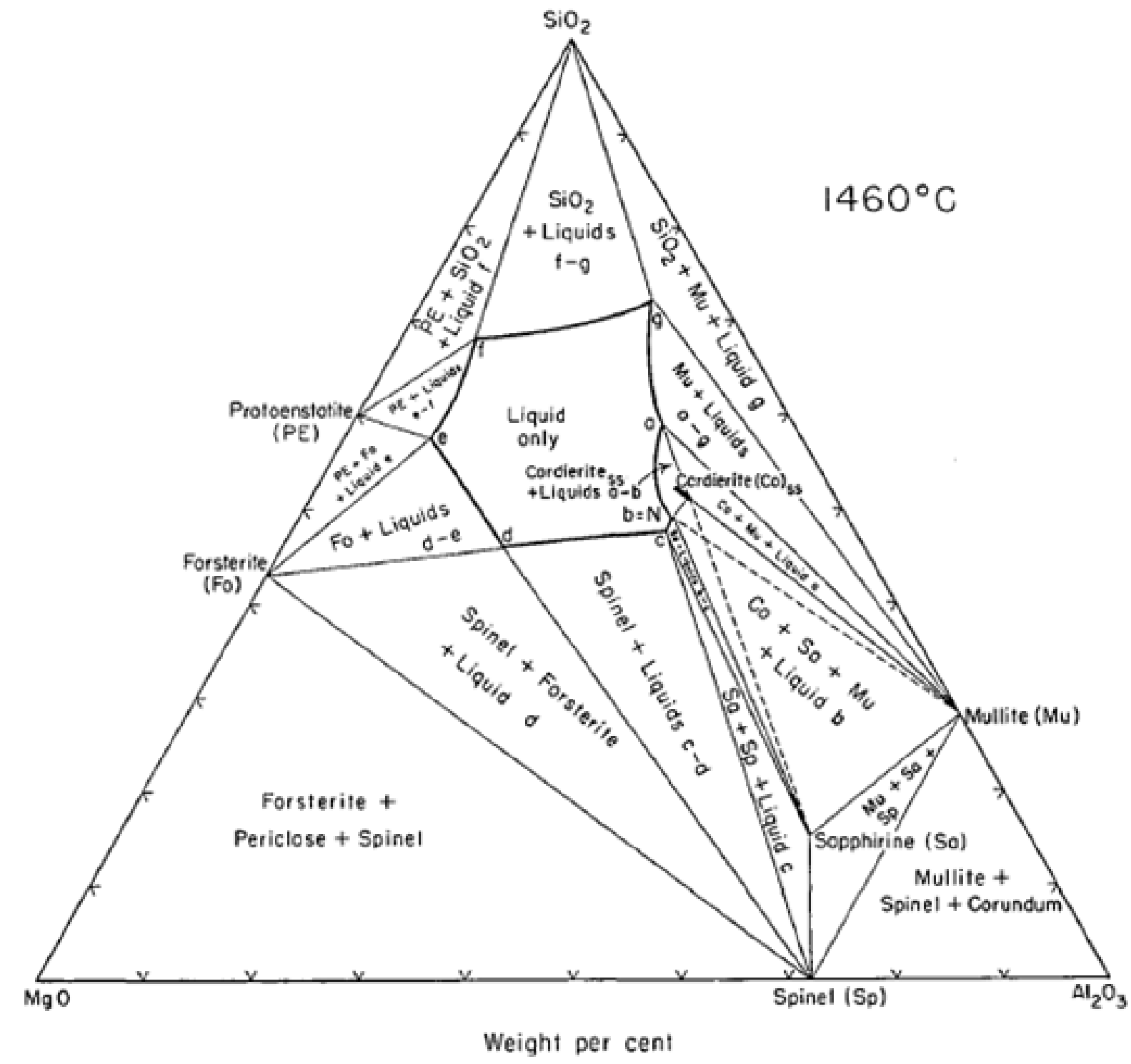

Figure 2. Isothermal section through the system $\mathrm{MgO}-\mathrm{Al}_{2} \mathrm{O}_{3}-\mathrm{SiO}_{2}$ at $1,460^{\circ} \mathrm{C}$. A binary range of cordierite solid solution (all solid at this temperature) is found, which is completely surrounded by multi-phase regions which also contain liquid fractions. For a full discussion of this phase diagram one is referred to the original manuscript [14]. The phase diagram is shown here to illustrate the complexity of the $\mathrm{MgO}-\mathrm{Al}_{2} \mathrm{O}_{3}-\mathrm{SiO}_{2}$ system at elevated temperatures (reproduced with permission). 
In the following sections we will describe two of the pathways of cordierite ceramics formation which were intensively studied in Daresbury laboratory with experimental set-ups that allowed such technique combinations. Both pathways involved high temperature treatments and the use of crystallization enhancers. An interesting aspect was that the role of the hetero-atoms $\left(\mathrm{Zn}^{2+}\right.$ or $\mathrm{Cr}^{3+}$ in this case) on the crystallization process can be studied, at the local atomic level, with the use of appropriate combined techniques.

\section{Materials and Methods}

The glass samples used in the in situ combined small-angle X-ray scattering and wide-angel X-ray scattering (SAXS/WAXS) and X-ray absorption spectroscopy (XAS) experiments were prepared by co-melting the ingredients and then rapidly cooled by pouring the material on a $\mathrm{Cu}$ plate. After this the samples were cut into platelets and slightly polished. For full details see[17]. Initial SAXS/WAXS experiments were carried out on beamline 8.2 of the SRS, Daresbury laboratory, UK and these were the firsts experiments carried out on that beamline in the SAXS/WAXS mode $[6,17,22]$. Experiments were later repeated with better temperature control [22] on BM26B at the ESRF [23]. EXAFS experiments were carried out on beam line 8.1 of the SRS Daresbury laboratory [24].

Zeolite B was synthesized based on the recipe provided in the patent[3]. In a typical synthesis, aluminium hydroxide, fumed silica and sodium hydroxide with appropriate ratios were mixed in water and the formed gel was subjected hydrothermal treatment. The final product was washed and dried before exchanging with magnesium chloride solution The ion-exchange was conducted at room temperature (RT) and the procedure was repeated three times to ensure complete exchange has taken place. This we term as $\mathrm{MgB}$ and was used for further studies. . XRD patterns of both as-synthesised and after ion-exchange with magnesium showed that zeolite B phase was the only one present in the sample. Combined XAS/XRD data were collected at 9.3 beam line at SRS, Daresbury laboratory which operated at $2 \mathrm{GeV}$ with a current of ca $150 \mathrm{~mA}$. Self-supporting wafers of the zeolite mixed with $1 \mathrm{wt} \% \mathrm{ZnO}$ was loaded in to a Linkam furnace and heated from RT to $1050{ }^{\circ} \mathrm{C}$. A total scan time of 600 seconds was used which includes $180 \mathrm{~s}$ for QEXAFS and $380 \mathrm{~s}$ for XRD. XAS data was collected in transmission mode and XRD was collected using an INEL detector at a wavelength of $1.299 \AA$ below the $\mathrm{Zn} \mathrm{K-edge} \mathrm{absorption} \mathrm{edge} \mathrm{to} \mathrm{avoid} \mathrm{fluorescence.} \mathrm{The} \mathrm{temperature} \mathrm{of} \mathrm{the} \mathrm{sample} \mathrm{was} \mathrm{raised}$ from RT to $300{ }^{\circ} \mathrm{C}$ at a rate of $2{ }^{\circ} \mathrm{C} / \mathrm{min}$, followed by $20^{\circ}{ }^{\circ} \mathrm{C} / \mathrm{min}$ from $300^{\circ}$ to $750^{\circ}{ }^{\circ} \mathrm{C}$ and 
from 750 to 1050 at $2^{\circ}{ }^{\circ} \mathrm{C} / \mathrm{min}$. EXAFS data were analysed using the Athena and Artemis software suites [25]

\section{Results and discussion}

First we discuss the influence of zinc cations in the conversion of a crystalline zeolitic solid (zeolite B) to crystalline cordierite phase through an amorphous intermediate followed by the role of chromium in the high temperature treatment of cordierite glass.

\section{Cordierite from Zeolite B}

Zeolite $\mathrm{B}$ has a typical composition of $\mathrm{Na}_{4} \mathrm{Al}_{4} \mathrm{Si}_{5} \mathrm{O}_{18}$ with $\mathrm{Si} / \mathrm{Al}$ ratio of 1.25 which is identical to that found in cordierite material. Therefore, when exchanged with $\mathrm{Mg}^{2+}$ (in place of $\mathrm{Na}^{+}, \mathrm{a}$ charge compensating cation) it should form the ideal composition to convert to crystalline cordierite[26]. It has been shown that this is the case and the conversion is shown to go via an amorphous intermediate before forming $\mu$-cordierite which gets converted to final cordierite ceramic phase. In an earlier work we demonstrated the power of combined XRD/XAS technique that a small amount of $\mathrm{ZnO}$ alter the transformation temperature[11]. Here we show a more detailed analysis of the combined XRD/XAS data with new insights which were gained since the time the experiments were carried out.

In Fig. 3 we show the stacked plot XRD data of $\mathrm{ZnO}$ mixed $\mathrm{MgB}$, collected at a wavelength of $1.299 \AA$, below the $\mathrm{Zn} \mathrm{K}$-edge, during the heat treatment process. XRD data of the $\mathrm{ZnO}$ mixed $\mathrm{MgB}$ shows the complete loss of reflections of zeolite $\mathrm{B}$ when heated above $300^{\circ} \mathrm{C}$ (consistent with the amorphous phase formation even without $\mathrm{ZnO}$ ) resulting in the formation of an amorphous intermediate which appears to continue to exist until a temperature of $900^{\circ} \mathrm{C}$ is reached; weak reflections of $\mathrm{ZnO}$ could be seen up to ca $800^{\circ} \mathrm{C}$, but due to low concentration it was not possible to quantify this. Above this temperature the $\mathrm{ZnO}$ phase disappears while it is still amorphous. Stuffed quartz starts to appear above $900^{\circ} \mathrm{C}$ and this appears to be an unstable phase and as it starts to disappear, simultaneously the cordierite phase starts to appear and remains stable. 


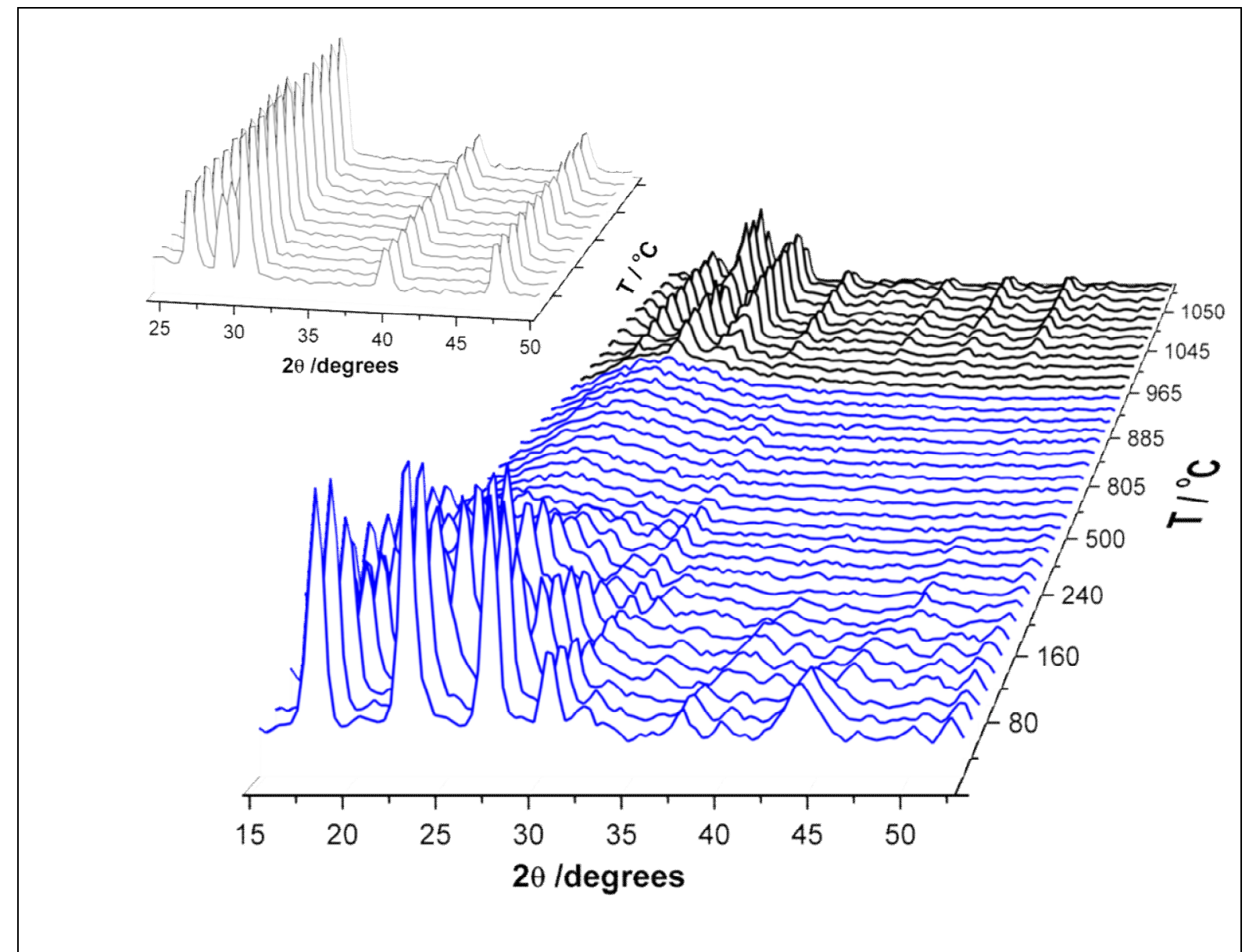

Figure 3: Stacked plot of XRD data collected while heating $\mathrm{ZnO}(1$ wt\%) mixed with magnesium exchanged zeolite B from room temperature to $1050^{\circ} \mathrm{C}$. Inset shows the stacked $X R D$ data collected while heating $\mathrm{ZnO}$ from room temperature to $1050^{\circ} \mathrm{C}$. Note that the XRD

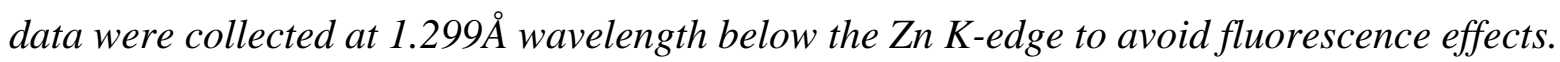

The events that are observed in the XRD data are summarized in figure 4, where we have plotted the intensity of one of the reflections of various phases present in the system. The following sequence of phase disappearance and appearance takes place: $25{ }^{\circ} \mathrm{C}>$ crystalline Zeolite $\mathrm{B}>300{ }^{\circ} \mathrm{C}>$ amorphous aluminosilicate $+\mathrm{ZnO}>800{ }^{\circ} \mathrm{C}>$ dissolution of $\mathrm{ZnO}>900$ ${ }^{\circ} \mathrm{C}>$ intermediate stuffed Quartz formation $>975{ }^{\circ} \mathrm{C}>$ crystalline Cordierite formation.

Whilst XRD data provided the unique information on the collapse of zeolite structure and some evidence for the $\mathrm{ZnO}$ being present in the system (weak reflections due to low concentration) 


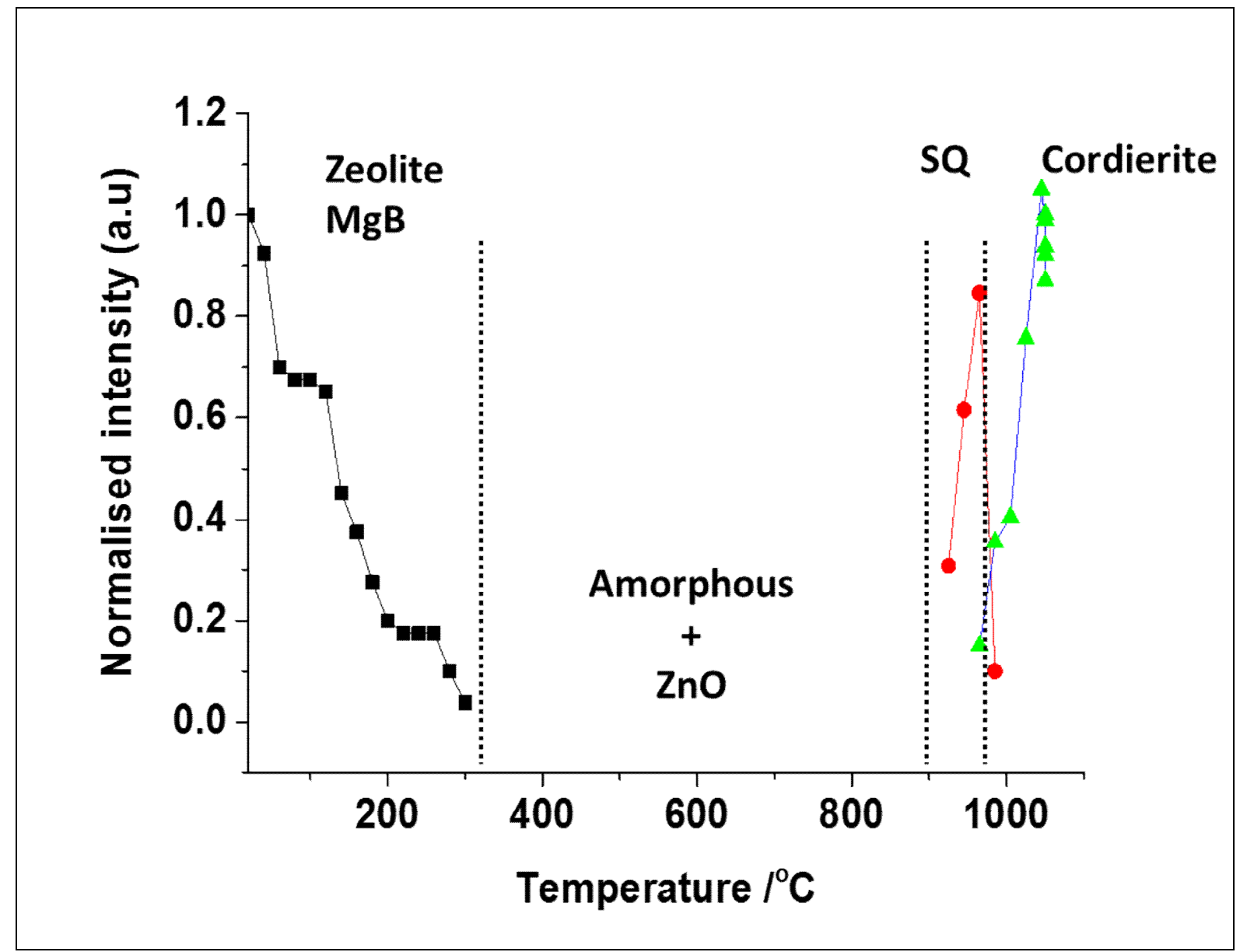

Figure 4. Changes in intensity of one of the reflection in XRD that corresponds to specific phases of Zeolite MgB, stuffed Quartz (SQ) and Cordierite vs temperature is shown here.

along with the amorphous system and dissolution of $\mathrm{ZnO}$ at temperatures above $800^{\circ} \mathrm{C}$ followed by the formation of stuffed quartz phase before forming the final cordierite phase, it was not possible to determine the fate of $\mathrm{Zn}$ (II) ions during the process. In order to evaluate the role of $\mathrm{ZnO}$ and its fate during the formation of cordierite from zeolite $\mathrm{B}$, we analysed the Zn K-edge EXAFS data in detail, which provided complete local structural changes that took place during the transformation process. In figure 5 we show stacked plot of Zn K-edge XAS data and the Fourier transform of the EXAFS data recorded during the heating process. From figure 5 we see that there a number changes at the Zn K-edge XAS that take place during the heat treatment process compared to pure $\mathrm{ZnO}$ heated at the same temperature 


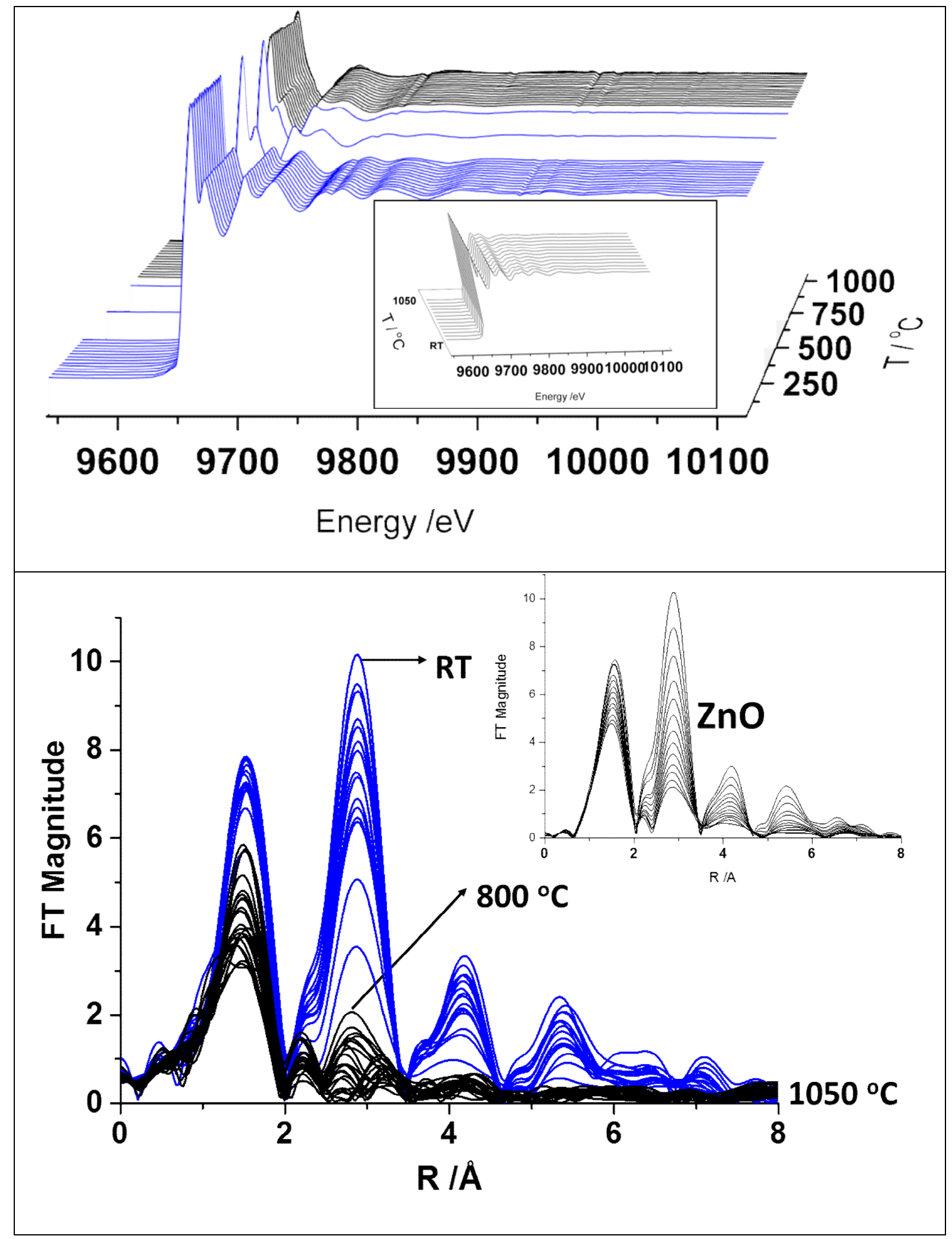

Figure 5 on the top we show the $\mathrm{Zn} \mathrm{K}$-edge XAS data of $\mathrm{ZnO}$ mixed $\mathrm{MgB}$ zeolite collected during the heat treatment and on the bottom the Fourier transforms of the EXAFS data obtained from the $\mathrm{Zn} \mathrm{K}$-edge data. Inset shows the pure $\mathrm{ZnO}$ heated to the same temperature. 
To understand more in detail, the $\mathrm{Zn} \mathrm{K}$-edge data was analysed to determine the nature of zinc environment that took place during the heat treatment process; heating $\mathrm{ZnO}$ to similar temperatures did not show a change in $\mathrm{Zn}-\mathrm{O}$ coordination number or $\mathrm{Zn}-\mathrm{O}$ interatomic distance within the experimental error. Plots of the variation in $\mathrm{Zn}-\mathrm{O}$ distance, coordination number and Debye-Waller factor (which consists of both static and dynamic disorder) for Zn-O atom pair are shown in figure 6, which are compared with pure $\mathrm{Zn}-\mathrm{O}$ measured at similar temperatures. The $\mathrm{Zn}-\mathrm{O}$ coordination number is not affected by this heat treatment and behaves very similar to pure $\mathrm{ZnO}$; changes in the higher shell are visible and different compared to pure $\mathrm{ZnO}$ heated to similar temperatures. However, both the $\mathrm{Zn}-\mathrm{O}$ distance and $\sigma^{2}$, the disorder parameter appears to be significantly affected, in particular above $c a 800{ }^{\circ} \mathrm{C}$. This seems to coincide with the dissolution of $\mathrm{ZnO}$ into the amorphous material prior to the formation of stuffed quartz phase as seen in XRD data. The Debye-Waller factor seem to deviate from the normal linear behaviour with temperature (as seen in the case of pure $\mathrm{ZnO}$ ) suggesting an increase in static disorder which could be the result of dissolution of $\mathrm{ZnO}$ into the amorphous zeolitic matrix. More importantly, the $\mathrm{Zn}-\mathrm{O}$ bond distance seems to decrease from ca $1.97 \AA$ recorded at the start (which is typical of $\mathrm{ZnO}$ wurtzite structure) to ca $1.94 \AA$ indicating the change in its phase composition. This $\mathrm{Zn}-\mathrm{O}$ distances is similar to the one seen in $\mathrm{ZnAl}_{2} \mathrm{O}_{4}$ where $\mathrm{Zn}$ occupies the A site and has a tetrahedral coordination with $\mathrm{Zn}-\mathrm{O}$ distance of ca 1.94 $\AA$. The spinel phase formation may have consumed any excess aluminium (deviation from $\mathrm{Si} / \mathrm{Al}$ ratio of 1.25$)$ in the system making the overall composition ideal for cordierite phase formation. 


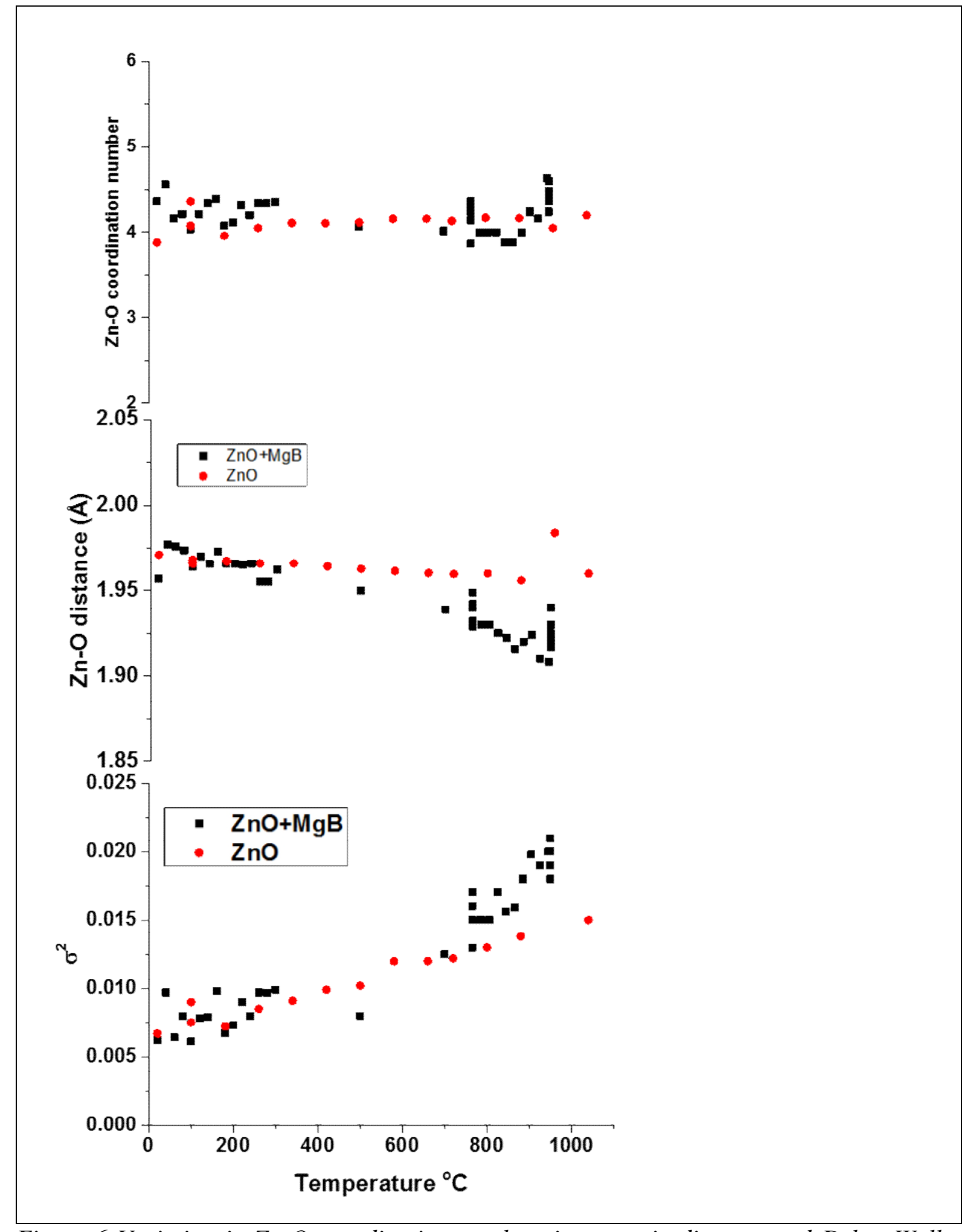

Figure 6 Variation in Zn-O coordination number, interatomic distance and Debye-Waller factor obtained from the analysis of $\mathrm{Zn} \mathrm{K}$-edge EXAFS data of $\mathrm{ZnO}$ mixed $\mathrm{MgB}$ sample with temperature. For comparison, pure $\mathrm{ZnO}$ was analysed and shown here. 


\section{Chromium containing cordierite glass}

Transformation of a glass starting material via thermally induced devitrification to a glass ceramic is a simple and often followed pathway. The temperatures required for the treatment of cordierite glasses are relatively high and therefore cost wise this may not be the most economical route but the attractiveness of the method lies in its simplicity. A model of the product can be pre-shaped and then brought to the required temperatures without any other processing step being required.

This route has been followed for a base glass with the cordierite composition which was doped with $0.34 \mathrm{~mol} \% \mathrm{Cr}_{2} \mathrm{O}_{3}$ as crystallisation enhancer. In order to be able to study the pure kinetics and also the role of the $\mathrm{Cr}$ in the crystallisation process one has to take care that the starting material is indeed fully amorphous which limits the allowed $\mathrm{Cr}$ concentration since if this is too high it is impossible to quench the melt fast enough to avoid crystallisation.

The glass was subjected to a two-step heat treatment, i.e. following the Tamman method [27], where the lower first step is used to induce crystallisation nuclei and the following higher treatment allows the nuclei to develop. The temperatures required are found by empirical means but in this way it is possible to create crystallites which from the onset are monodisperse and grow at the same rate till the later stages where either Ostwald ripening can take over or where the crystalline volume becomes space filling. Part of the results obtained have been published before $[17,28]$ and will be only briefly summarised here. After that we focus here on some later insights and also show some later results. What exactly happens during the first part of the thermal treatment cannot be elucidated by diffraction or scattering methods since the nuclei are structurally too small and below the detection limit. Here one can revert to X-ray absorption spectroscopy which can provide information on the local $\mathrm{Cr}$ environment and thus can shine a light on its role as crystallisation enhancer as well.

In an earlier study using EPR [19] it was suggested that the Cr initially clustered before being transformed into a mixed $\mathrm{Cr}-\mathrm{Al}$ spinel. EXAFS experiments [17, 23], however, showed no sign of such clustering but instead showed the formation of a $\mathrm{Cr}$ rich spinel with composition $\mathrm{MgCr}_{0.18} \mathrm{Al}_{1.82} \mathrm{O}_{4}$. This is in agreement with the electron density differences found from the $\mathrm{X}$ ray scattering data which points to an initial homogeneous distribution of $\mathrm{Cr}$ throughout the glass but at later stages a nearly complete consumption of the $\mathrm{Cr}$ in the spinel particles. 
Samples that had been subjected to the two-step heat treatment were characterized by XRD, after the on-line time-resolved SAXS/WAXS experiments, for phase determination and SEM/TEM for the morphological information. XRD shows that there are two crystalline phases, spinel and $\mu$-cordierite (stuffed quartz), present but that the bulk of the material is still in a glassy state. The SEM shows that there exists a difference between the surface and the bulk of the samples. TEM confirms the presence of nano crystals in a glassy matrix (see figure 7). It was impossible to determine the crystalline phase by electron diffraction due to the fact that the crystallites started to rotate under the influence of the electron beam.
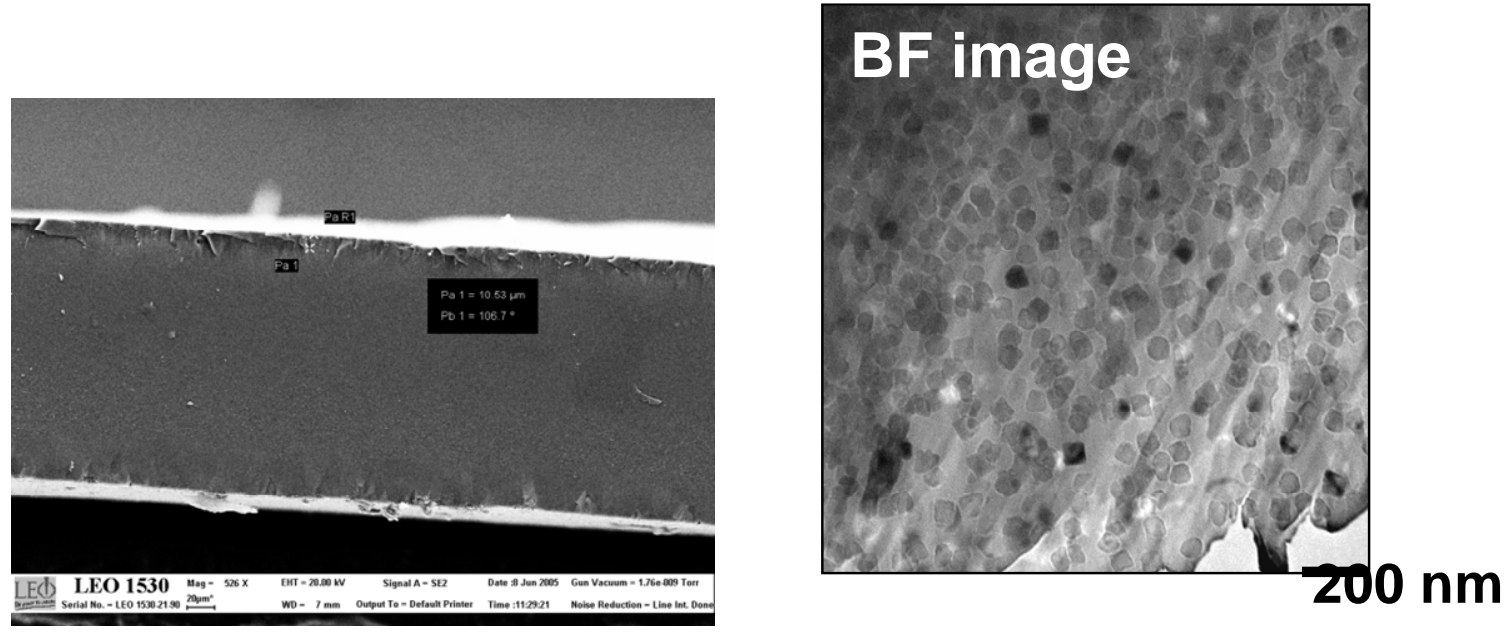

Figure 7 Left hand side SEM of a cordierite platelet after heat treatment. The data are taken from a freshly cleaved samples and represent a transverse view. (SEM courtesy of I. Snigireva, ESRF, Grenoble) the surface is characterized by conchoidal fractures whilst the bulk is much more uniform. Right hand side TEM of the same platelet. The dark crystallites have a cuboidal shape. (TEM courtesy of Velimir Radmilovic, NCEM, Lawrence Berkeley Laboratory)

The time-resolved SAXS/WAXS data, obtained during the second stage of the heat treatment shows a correlation between the growth of the spinel phase and the increase in SAXS intensity. At a later stage the SAXS pattern shows a pattern characteristic of rather monodisperse particles. Diffraction intensity in the wider angle scattering range shows that the spinel phase starts to grow first. See figure 8. Although the time correlation with the SAXS data is not exact it is clear that the two phenomena are correlated. The slight time-gap can be explained by the 
fact that SAXS is more sensitive with respect to the onset of crystallization compared to WAXS. For SAXS only a somewhat increased long range density variation has to appear whilst in order for diffraction peaks to appear a large enough reasonable ordered crystal has to be formed. The earliest stages where due to the small crystallite size the Scherrer broadening is still relevant and the disorder intrinsic to the earliest stages of nano crystal formation preclude the detection of diffraction peaks [29].

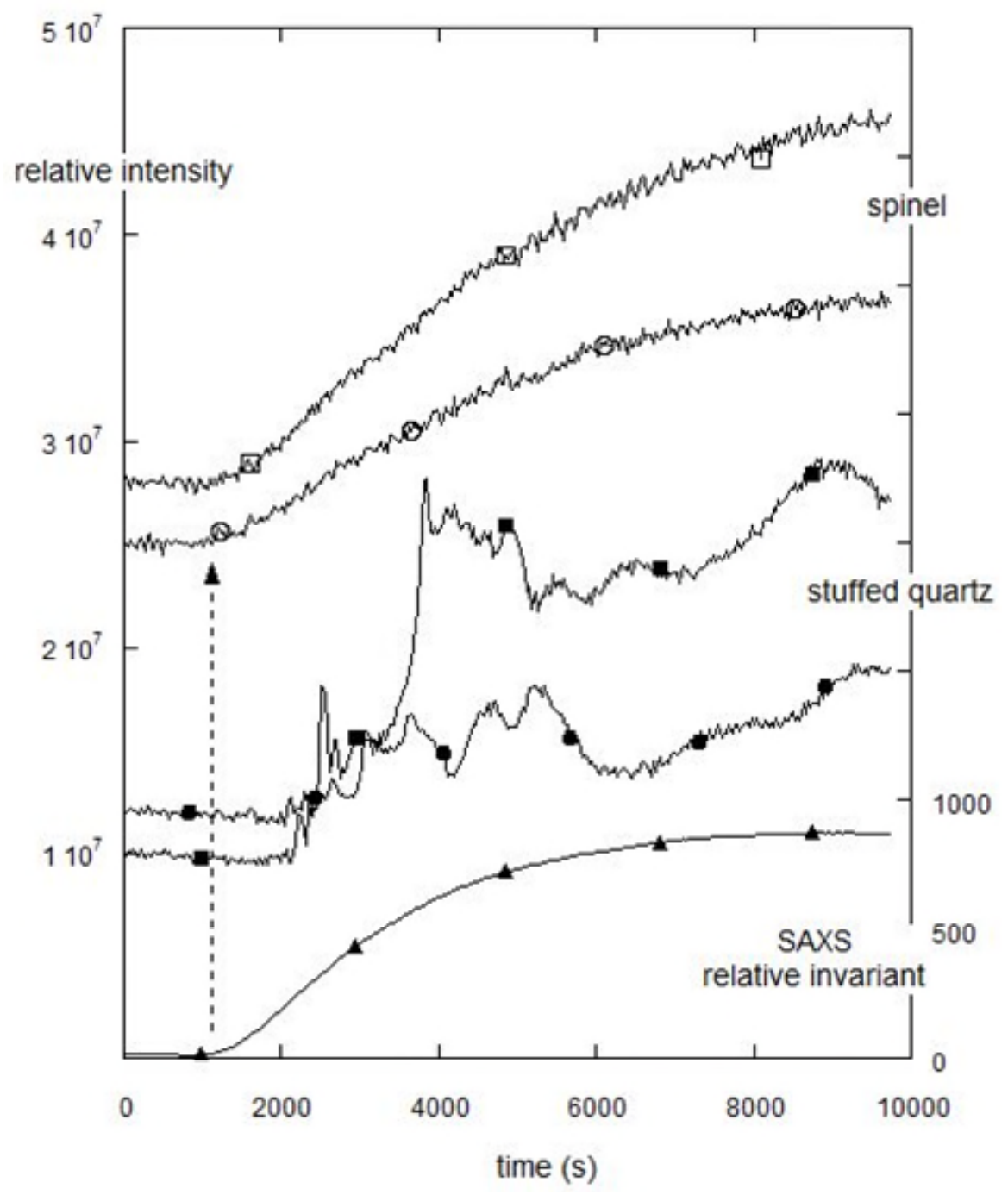

Figure 8 Time evolution of selected spinel diffraction peaks (open symbols), stuffed quartz (closed symbols) and the total scattered SAXS intensity (closed triangles). The dotted arrow is intended as a guide to the eye and serves to indicate the time correlation between the total SAXS intensity and the start of the spinel peaks, as well as the to indicate the time gap between the start of the spinel and the stuffed quartz. The non-correlated variation changes in the stuffed quartz peaks points to a developing texture (The curves of the diffraction peaks are offset for clarity) 
The $\mu$-cordierite phase starts to grow after the formation of the spinel has started. Keeping in mind that the phase diagram is rather complicated and that local compositional changes correlated with the formation of the spinel can occur the question becomes if the two crystallization processes are correlated and that for instance a kind of core (spinel) - shell ( $\mu$-cordierite) could be formed [20]. In theory the SAXS data could provide the answer but with some polydispersity and a low crystalline volume fraction the time-resolved data lacks the quality to be allowed to do such analysis. One could argue that a higher intensity X-ray beam could improve the statistical data quality but here one can fall into one of the pitfalls of modern synchrotron beamlines where the intensity is so high that the photo electrons which are generated by X-ray absorption, start to interfere with the crystallization process in either a destructive or constructive way [30,31]. In this case the WAXS data, in combination with the SEM data, provides the answer. Whilst the spinel volume fraction increases in a monotonous way, the stuffed quartz crystalline peak intensity increases erratically. See figure 8 . This indicates that one is not dealing with a randomly oriented material but instead with a crystalline fraction that is textured and of which the texture is changing during the growth process. This indicates that the stuffed quartz is being formed on the surface of the glass platelets and is not associated with the growth of the bulk spinel phase. The conchoidal fracture visible in the SEM shows the extent of the stuffed quartz surface layer.

Here one can reflect for a moment on the luck of the experimenter. If these experiments had been carried out with a powdered sample the stuffed quartz would also have seen a random orientation and the increase in stuffed quartz volume fraction would also have been perceived as monotonous. The downside of this is that it is impossible to determine the crystallization kinetics of the stuffed quartz in this experiment and one has to revert to other methods [32].

Another interesting aspect is that the unit cell sizes of both crystalline phases are continuously changing. For the stuffed quartz one observes an elongation of the unit cell and a decrease of the total volume. This change is monotonous. See figure 9. In contrast the change in the spinel unit cell is not continuous. At the initial stages the nano crystals show a decreasing unit cell size. When the increase in average crystal radius, $R$, as determined by SAXS, slows down, i.e. the particle growth does not follow the $R(t) v s \sqrt{t}$ growth behaviour anymore, the unit cell size 


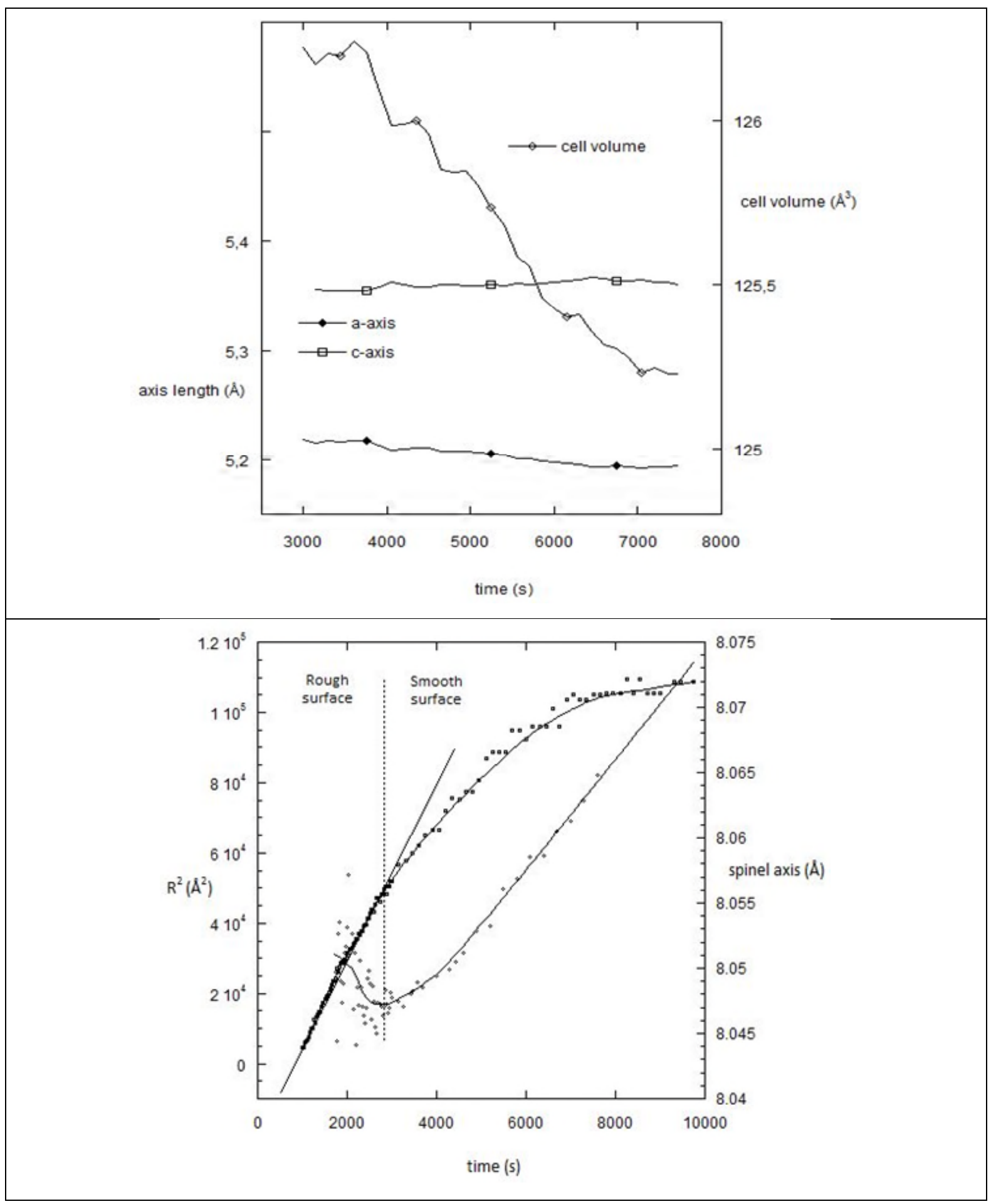

Figure 9. Changes in unit cell size for the stuffed quart (top) and changes in the unit cell size of the spinel correlated with the growth of the spinel crystallites (bottom). The dotted line indicates where the crystallites leave the free growth regime which coincides with the moment that the spinel crystalline unit cell starts to increase in size. From earlier experiments [17] it is also known that at this stage the interface between the crystallites and the surrounding glass matrix starts to become smoother (rough vs smooth surface). 
starts to increase again. This is also the moment that the crystalline nanoparticles surface roughness starts to smoothen out.

It is not uncommon that the crystalline unit cell for nano crystals is not identical to the values reported for the same material in the bulk state [33]. In this experiment we see changes occurring for both phases. The stuffed quartz forms on the surface and has a tendency to grow 'into' the bulk forming a textured layer with the c-axis at right angles with the sample surface [34]. Here we see that, the unit cell appears to increase as the surface layer becomes thick.

For the spinel, once the growth process slows down sufficiently that the surface tension can be minimized and a smooth crystallite/matrix is formed, the unit cell starts to increase. Earlier we have shown that this was due to the fact that the specific volume of the spinel phase is smaller than that of the glassy state and that therefore the matrix exerts a considerable force on the crystallites which cause them to expand. This finding allows one to create a composite material with pre-stressed centers with a stress level that can be influenced by the thermal treatment.

We now return to the role of the crystallization enhancer in the form of the $\mathrm{Cr}$ addition. From the experiments above it is not clear if the $\mathrm{Cr}$ is involved in the formation of the spinel phase or of the stuffed quartz. Intuitively one would guess the spinel which is formed first. This intuition is confirmed by neutron scattering experiments on the cooled samples [19]. In these experiments one only observes the structure factor peak in the SAXS pattern and a notable absence of form factor intensity fringes. When one compares the neutron scattering length and the X-ray scattering cross section of the elements making up the samples, it is clear that only $\mathrm{Cr}$ in the $\mathrm{X}$-ray case stands out as a strong scatterer. This is illustrated in figure 10. 


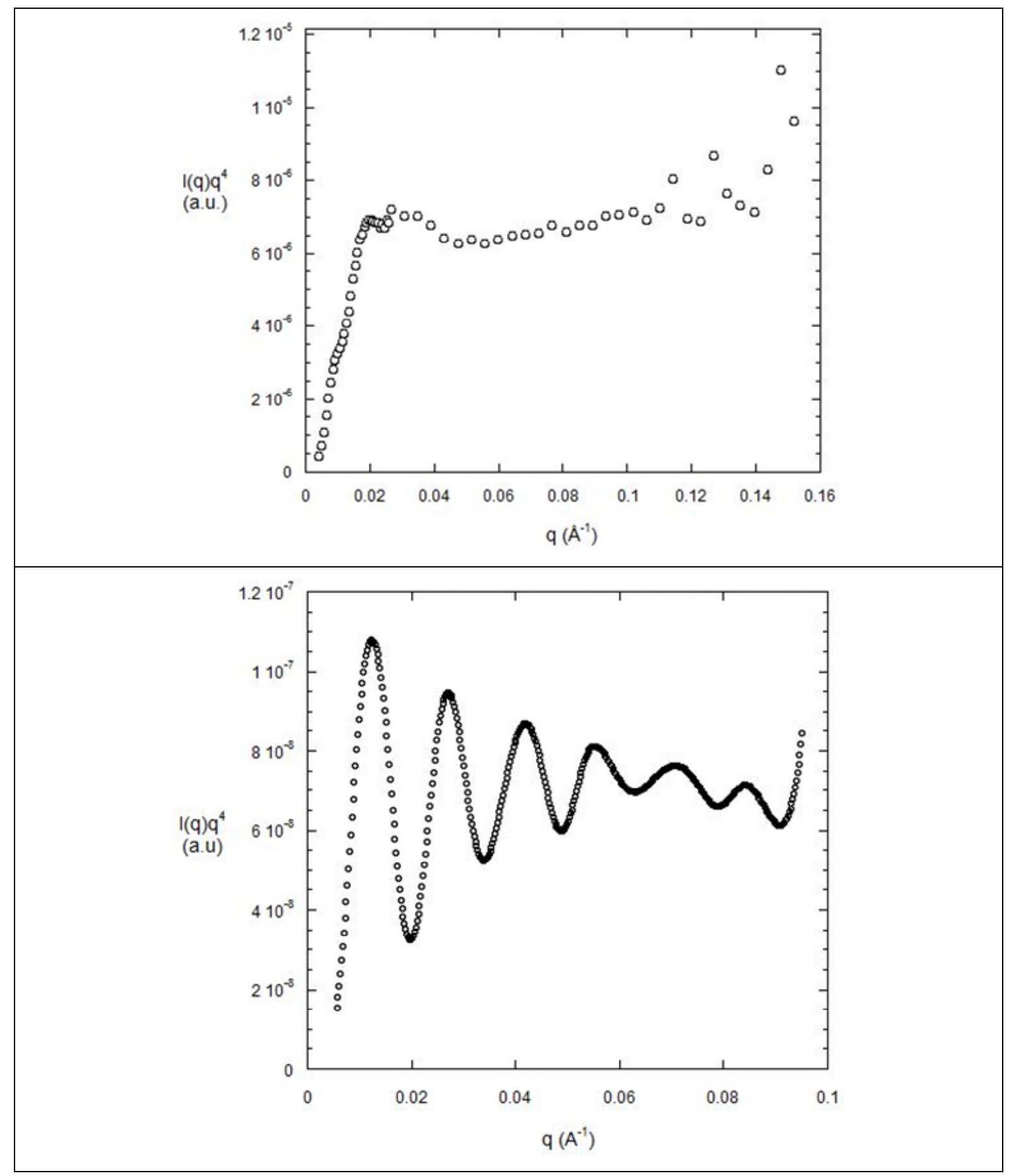

Figure 10 SANS (top) and SAXS (bottom) patterns from the same sample. In the SANS pattern one can just discern the first two scattering maxima of the scattering pattern that are clearly visible in the SAXS pattern. This indicates that the scattering contrast in the case of SAXS is much higher compared to the SANS data. A comparison of the different sample components points to the fact that $\mathrm{Cr}$ is the only elemental component which could give rise to this effect and therefore must be associated with the Cr-spinel formation in the sample. This is a very clear example what contrast variation methods can be used for. 
When one considers the complicated phase diagram that guides cordierite glass ceramics creation it should not come as a surprise that, upon a heat treatment, different crystalline phases are being formed from the original glass matrix. The nucleation of the different phases on the surface and in the bulk have different origins. Surface inhomogeneities act as the nucleating agent for the surface crystallization whereas the presence of $\mathrm{Cr}$, or probably any other crystallization enhancer, is required for the formation of bulk crystallites in the time scales that were studied here. The fact that the bulk spinel crystallization stalls, and the fact that $\mathrm{Cr}$ could be associated with this specific crystal, both via EXAFS as well as via contrast variation methods using both X-ray as well as neutron scattering, indicates that the presence of this crystallization enhancer determines the final degree of crystallization that is feasible.

\section{Conclusions}

In the examples sketched above we showed that even for a relatively simple problem, as the creation of glass ceramics which can be interesting from a materials science point of view, a multitude of preparation methods, as well as a great variety of physical characterization techniques, are required to fully evaluate the influence of dopant ions that promote or retard the formation of ceramic cordierite. In this case there is a crucial role for on-line, in-situ methods which can mimic the industrial processes by which these materials are being created.

Whilst spinel formation $\left(\mathrm{ZnAl}_{2} \mathrm{O}_{4}\right)$ in the case of zinc oxide mixed zeolite $\mathrm{B}$ or $\mathrm{Mg} \mathrm{Cr}_{2} \mathrm{O}_{4}$ in the case of chromium doped cordierite glass) appears to be a common theme in the examples showed here, in the case of zeolite B it appears to promote the formation of cordierite at lower temperatures whereas it retards in the case of $\mathrm{Cr}$ doped cordierite glass. In the $\mathrm{ZnO}$ mixed system, we believe that the spinel formation may remove some of the excess $\mathrm{Al}^{3+}$ to shift the equilibrium to promote the formation of cordierite. On the other hand $\mathrm{Cr}$ ions which occupy the B site, seem to remove the required magnesium ions to form spinel which probably shift the equilibrium in the opposite direction which seems to retard the transformation of cordierite. Therefore, in order to be able to understand the role of the different preparation methods, the crystallization additives, and the time evolution of the materials, which are all part of the empirical knowledge but not necessarily understood at the different length scales relevant for the formation of these materials, one requires a plethora of experimental techniques. 


\section{Acknowledgements}

Jan Kihle is gratefully acknowledged for permission to reproduce the Iolite figure (1). The development of the infrastructure to be able to combine experiments on-line was driven by the insights and enthusiasm of G. Neville Greaves. Gareth Derbyshire, Geoff Mant, Simon Clark have been involved in these instrumentation developments at different stages.

\section{References}

[1] L.K. Karlsen, Secrets of the Viking Navigators, One Earth Press, 2003.

[2] J.B. Kihle, World's greatest cordierite find?, Norsk Bergverksmuseum Skrifter. , 50 (2013) 59-62.

[3] R.L. Bedard, E.M. Flanigen, in: US patent no. 4,980,323, USA, 1990.

[4] W. Bras, A.J. Ryan, Sample environments and techniques combined with Small Angle X-ray Scattering, Advances in Colloid and Interface Science, 75 (1998) 1-43.

[5] A.J. Dent, M.P. Wells, R.C. Farrow, C.A. Ramsdale, G.E. Derbyshire, G.N. Greaves, J.W. Couves, J.M. Thomas, COMBINED ENERGY DISPERSIVE EXAFS AND X-RAY-DIFFRACTION, Review of Scientific Instruments, 63 (1992) 903-906.

[6] W. Bras, G.E. Derbyshire, A.J. Ryan, G.R. Mant, A. Felton, R.A. Lewis, C.J. Hall, G.N. Greaves, Simultaneous Time Resolved Saxs and Waxs Experiments Using Synchrotron Radiation, Nuclear Instruments \& Methods in Physics Research Section a-Accelerators Spectrometers Detectors and Associated Equipment, 326 (1993) 587-591.

[7] A.M. Beale, G. Sankar, Understanding the crystallization of nanosized cobalt aluminate spinel from ion-exchanged zeolites using combined in situ QEXAFS/XRD, Chemistry of Materials, 18 (2006) 263-272.

[8] B.S. Clausen, L. Grabaek, G. Steffensen, P.L. Hansen, H. Topsoe, A COMBINED QEXAFS XRD METHOD FOR ONLINE, IN-SITU STUDIES OF CATALYSTS - EXAMPLES OF DYNAMIC MEASUREMENTS OF CU-BASED METHANOL CATALYSTS, Catalysis Letters, 20 (1993) 23-36.

[9] B.S. Clausen, H. Topsoe, R. Frahm, Application of combined X-ray diffraction and absorption techniques for in situ catalyst characterization, in: D.D. Eley, W.O. Haag, B. Gates, H. Knozinger (Eds.) Advances in Catalysis, Vol 42, 1998, pp. 315-344.

[10] J.W. Couves, J.M. Thomas, D. Waller, R.H. Jones, A.J. Dent, G.E. Derbyshire, G.N. Greaves, TRACING THE CONVERSION OF AURICHALCITE TO A COPPER CATALYST BY COMBINED X-RAY ABSORPTION AND DIFFRACTION, Nature, 354 (1991) 465-468.

[11] G. Sankar, P.A. Wright, S. Natarajan, J.M. Thomas, G.N. Greaves, A.J. Dent, B.R. Dobson, C.A. Ramsdale, R.H. Jones, COMBINED QUEXAFS-XRD - A NEW TECHNIQUE IN HIGH-TEMPERATURE MATERIALS CHEMISTRY - AN ILLUSTRATIVE IN-SITU STUDY OF THE ZINC OXIDE-ENHANCED SOLIDSTATE PRODUCTION OF CORDIERITE FROM A PRECURSOR ZEOLITE, Journal of Physical Chemistry, 97 (1993) 9550-9554.

[12] I.J. Shannon, F. Rey, G. Sankar, J.M. Thomas, T. Maschmeyer, A.M. Waller, A.E. Palomares, A. Corma, A.J. Dent, G.N. Greaves, Hydrotalcite-derived mixed oxides containing copper: Catalysts for the removal of nitric oxide, Journal of the Chemical Society-Faraday Transactions, 92 (1996) 43314336.

[13] J.M. Thomas, G.N. Greaves, COMBINED EXAFS AND XRD FOR THE IN-SITU STRUCTURAL ELUCIDATION OF SOLID CATALYSTS UNDER OPERATING-CONDITIONS, Catalysis Letters, 20 (1993) 337-343.

[14] W. Schreyer, J.F. Schairer, Compositions and Structural States of Anhydrous Mg-Cordierites - a Re-Investigation of the Central Part of the System Mgo-Al2o3-Sio2, Journal of Petrology, 2 (1961) 324-406. 
[15] J.P. Dong, W. Chen, L. Luo, Effects of $\mathrm{Cr} 2 \mathrm{O} 3$ additive on crystallization behavior of MgO-Al2O3SiO2-TiO2 glass-ceramics, Journal of Inorganic Materials, 21 (2006) 1060-1066.

[16] G. Sankar, P A Wright, S Natarajan, J M Thomas, G N Greaves, A J Dent, B R Dobson, C A Ramsdale, R.H. Jones, Combined Quexafs-Xrd - a New Technique in High-Temperature Materials Chemistry - an Illustrative in-Situ Study of the Zinc Oxide-Enhanced Solid-State Production of Cordierite from a Precursor Zeolite, J. Phys. Chem., 97 (1993) 9550.

[17] W. Bras, G.N. Greaves, M. Oversluizen, S.M. Clark, G. Eeckhaut, The development of monodispersed alumino-chromate spinel nanoparticles in doped cordierite glass, studied by in situ $\mathrm{X}$-ray small and wide angle scattering, and chromium X-ray spectroscopy, Journal of Non-Crystalline Solids, 351 (2005) 2178-2193.

[18] S.B. Sohn, S.Y. Choi, Crystallization behavior in the glass system MgO-Al2O3-SiO2: influence of CeO2 addition, Journal of Non-Crystalline Solids, 282 (2001) 221-227.

[19] F. Durville, B. Champagnon, E. Duval, G. Boulon, F. Gaume, A.F. Wright, A.N. Fitch, Nucleation Induced In A Cordierite Glass By Cr-3+ - A Study By Small-Angle Neutron-Scattering, ElectronParamagnetic Resonance And Laser Spectroscopy, Physics And Chemistry Of Glasses, 25 (1984) 126133.

[20] C. Patzig, T. Hoeche, Temporal Evolution of Crystallization in MgO-Al2O3-SiO2-ZrO2 Glass Ceramics, Crystal Growth \& Design, 12 2059-2067.

[21] E. Chason, M.J. Aziz, Effect of Pressure on Crystallization Kinetics of Cordierite Glass, Journal of Non-Crystalline Solids, 130 (1991) 204-210.

[22] A.J. Dent, M. Oversluizen, G.N. Greaves, M.A. Roberts, G. Sankar, C.R.A. Catlow, J.M. Thomas, A Furnace Design for Use in Combined X-Ray-Absorption and Diffraction up to a Temperature of 1200Degrees-C - Study of Cordierite Ceramic Formation Using Fluorescence Qexafs/Xrd, Physica B, 209 (1995) 253-255.

[23] W. Bras, I.P. Dolbnya, D. Detollenaere, R. van Tol, M. Malfois, G.N. Greaves, A.J. Ryan, E. Heeley, Recent experiments on a combined small-angle/wide-angle X-ray scattering beam line at the ESRF, Journal of Applied Crystallography, 36 (2003) 791-794.

[24] M.J. Vanderhoek, W. Werner, P. Vanzuylen, B.R. Dobson, S.S. Hasnain, J.S. Worgan, G. Luijckx, A SLITLESS DOUBLE CRYSTAL MONOCHROMATOR FOR EXAFS AND XANES MEASUREMENTS, Nuclear Instruments \& Methods in Physics Research Section a-Accelerators Spectrometers Detectors and Associated Equipment, 246 (1986) 380-384.

[25] B. Ravel, M. Newville, ATHENA, ARTEMIS, HEPHAESTUS: data analysis for X-ray absorption spectroscopy using IFEFFIT, Journal of Synchrotron Radiation, 12 (2005) 537-541.

[26] M.A. Subramanian, D.R. Corbin, U. Chowdhry, BETTER CERAMIC SUBSTRATES THROUGH ZEOLITES, Bulletin of Materials Science, 16 (1993) 665-678.

[27] G. Tammann, Z. Phys. Chem., (1898) 441.

[28] W. Bras, S M Clark, G N Greaves, M Kunz, W van Beek, V. Radmilovic, Nanocrystal Growth in Cordierite Glass Ceramics Studied with X-ray Scattering, Crystal Growth Design, 9 (2009) 1297.

[29] W. Bras, S. Koizumi, N.J. Terrill, Beyond simple small-angle X-ray scattering: developments in online complementary techniques and sample environments, IUCrJ, 1 (2014).

[30] V. Martis, S. Nikitenko, S. Sen, G. Sankar, W. van Beek, Y. Filinchuk, I. Snigireva, W. Bras, Effects of X-rays on Crystal Nucleation in Lithium Disilicate, Crystal Growth \& Design, 11 (2011) 2858-2865. [31] H.B. Stanley, D. Banerjee, L. van Breemen, J. Ciston, C.H. Liebscher, V. Martis, D.H. Merino, A. Longo, P. Pattison, G.W.M. Peters, G. Portale, S. Sen, W. Bras, X-ray irradiation induced reduction and nanoclustering of lead in borosilicate glass, Crystengcomm, 16 (2014) 9331-9339.

[32] R. Muller, R. Naumann, S. Reinsch, Surface nucleation of mu-cordierite in cordierite glass: Thermodynamic aspects, Thermochimica Acta, 280 (1996) 191-204.

[33] P.M. Diehm, P. Agoston, K. Albe, Size-Dependent Lattice Expansion in Nanoparticles: Reality or Anomaly?, Chemphyschem, 13 (2012) 2443-2454.

[34] N. Diaz-Mora, E.D. Zanotto, R. Hergt, R. Muller, Surface crystallization and texture in cordierite glasses, Journal of Non-Crystalline Solids, 273 (2000) 81-93. 
